\title{
Food Security, Conservation Agriculture and Pulses: Evidence from Smallholder Farmers in Zambia
}

\author{
Progress H. Nyanga \\ Department of International Environment and Development Studies (Noragric) \\ Norwegian University of Life Sciences, P.O Box 5003, NO-1432 Ås, Norway \\ Tel: 47-4770-7345/260-979-922-201Ｅ-mail: pnyanga@yahoo.co.uk, progress.nyanga@umb.no
}

\author{
Received: March 27, 2012 Accepted: April 6, $2012 \quad$ Published: May 1, 2012 \\ doi:10.5539/jfr.v1n2p120 \\ URL: http://dx.doi.org/10.5539/jfr.v1n2p120
}

This study was conducted under Conservation Agriculture Programme in Zambia funded by the Norwegian Ministry of Foreign Affairs through the Royal Norwegian Embassy in Lusaka to the Conservation Farming Unit of the Zambia National farmers Union. The views expressed in this paper are not of the sponsors but the author's

\begin{abstract}
Food insecurity is common place among 44\% (six million) of Zambian population. Conservation agriculture (CA) is an option being promoted to address this problem. There is little evidence showing whether CA adopters are better than non-CA adopters in terms of food security. Using a four years panel data, focus group discussions, key informant interviews, informal discussions and personal observations, this study documents the differences in household food security between CA adopters and non-CA adopters in relation to pulses. Results showed that most common pulses grown among smallholder farmers were groundnuts, cowpeas, soya beans and other beans. A tendency for the percentage of households growing pulses to be significantly higher among CA-adopters than among non-CA adopters was recorded. Cash income from pulses as percentage of total pulses production was significantly higher among CA adopters than among non-CA adopter in all the four years. Similar results were obtained for crop diversity and mean number of meals with pulses eaten in a day. Cases of women increasing their cash income from pulses because of CA practices were also reported. Focus group discussants explained that CA had reduced the intensity of food shortage during the peak hunger period because of early green harvest. With reference to pulses, it is concluded from this study that, among sampled smallholder farmers, CA adopters are relatively more food secure than non-CA adopters. Factors contributing to increased food security included farmer trainings in CA, increased access to planting seed, early land preparation and planting, and revitalisation of the practice of crop rotation.
\end{abstract}

Keywords: Livelihood security, Climate change, Gender, Food security, Climate smart agriculture

\section{Introduction}

Food insecurity is a day to day experience for hundreds of millions of people in the world. About $13 \%$ of the world population are undernourished (FAOSTAT, 2011). This means about one billion people continuously experience food deprivation. The hot spots of food insecurity are in South Asia and Sub-Saharan Africa marked by favourable progress in Asia but sluggish progress in Sub-Saharan Africa (Wiesmann, 2006). Percentage of undernourishment is higher in Sub-Saharan Africa (35\% and above) compared to most regions in the world (UN, 2011). Zambia is among countries in Sub-Saharan Africa with highest levels of undernourishment. About $44 \%$ of the Zambian population experience food deprivation (FAOSTAT, 2011; UNPFA, 2011). The country has recorded almost no progress towards meeting the millennium development goal of reducing hunger. The proportion of undernourishment has increased from about $35 \%$ in the early $1990 \mathrm{~s}$ to $38 \%$ (3 million) in the mid 1990 s, $43 \%$ (3.6 million) in the early 2000 and 44\% (6 million) towards 2011(FAO, 2010a).

The state of food insecurity in the world report defines food security as: "exists when all people, at all times, have physical, social and economic access to sufficient, safe and nutritious food that meets their dietary needs and food preferences for an active and healthy life" (FAO, 2010b:8). The key dimensions of food security are food availability, food access, food utilization and stability. 
Food availability relates to physical presence of sufficient quantity and appropriate quality of food from own production, stocks, markets, food aid and communal resources (Siamwalla \& Valdes, 1980; Ziervogel \& Ericksen, 2010). Food availability at higher aggregated levels is a necessary but not sufficient condition for attaining food security at segregated levels (Devereux \& Edwards, 2004; Renzaho \& Mellor, 2010). This is because of limitation in physical, social, institutional and economic access to food by households and individuals.

The access dimension of food security includes sub components of physical access (ability to physically acquire food), economic access (ability to buy food) and social access (ability to acquire food through social capital) (World Food Programme, 2004). However, food access is not a guarantee for food security without addressing the food utilization dimension (Webb et al., 2006).

The dimension of food utilisation has two components: consumption and nutrition. The former refers to the quantity and quality of dietary intake while the latter refers to the extent to which the body is able to make best use of the nutrients from the consumed food in order to have an active and healthy life (Renzaho \& Mellor, 2010; Riely, Mock, Cogill, Bailey, \& Kenefick, 1999). Alternatively, food utilisation consists of ability to have physical means to use food available and ability of the body to use the nutrients effectively once the food is consumed (Renzaho \& Mellor, 2010). The food culture, peoples' preferences, knowledge, assets, disease and sanitation are among cardinal elements of food utilisation dimension of food security concept.

The stability dimension addresses the "at all times" part of the food security definition in relation to the above three dimensions. This considers seasonality and vulnerability context of food security, thus need for stability in food availability, stability in access to adequate quantity and quality of preferred food and stability in food utilisation (Burchi, Fanzo \& Frison, 2011). The stability dimension of food security requires asset creation and institutional building (Renzaho \& Mellor, 2010).

\subsection{Causes of food insecurity}

Literature below shows that there are multiple layers of causes of food insecurity. No single factor is sufficient to explain adequately food insecurity situation in most of the developing countries. This section shows several factors that often interact to cause food insecurity in most developing countries.

\subsubsection{Governance, structural, policy and institutional failures}

von Braun (2010) contends that food insecurity is due to failures in governance of agriculture, food and nutrition. In order to address food insecurity there is need for the establishment of a global legitimate body to address the following: Research and innovation for improving agricultural productivity and ensuring food security; food emergencies through monitoring, responding to and preventing crises; health through improving food safety and setting health and nutrition standards; effective climate change adaptation and mitigation; prevention of excessive speculation in food markets and wild food price volatility; trade and investment by setting policies for trade of food reserves and standards for foreign investment that protect the poor; and promote environmental sustainability by protecting soils against degradation, promoting biodiversity and improving water use (von Braun, 2010).

Several structural and institutional failures contribute to food insecurity. These include increased inequalities in access to and control over resources; policy failures regarding smallholder producers; under-investment in agriculture, rural development and infrastructure; lack of consistency in effective operation of markets; and inadequate safety nets and social protection systems (High-Level Task Force on Global Food Security, 2010). Unhelpful or inconsistent government policies and programs also contribute towards food insecurity in most of the developing countries (Devereux, 2000; Tschirley \& Jayne, 2010).

von Braun et al. (2012), point out that the lack of inter sectoral cooperation in generating solutions to the complex problem of food insecurity compromises efforts to enhance food security. In order to increase agricultural production and productivity, there is need for a healthy human capital and agriculture is a major source of valuable food needed for an active and health life (Asenso-Okyere, Chiang, Thangata \& Andam, 2012). This literature suggests need for a collaborative involvement of the health sector, nutrition sector and agricultural sector in development interventions addressing food insecurity.

\subsubsection{Gender gaps and poverty}

Between 60 and $70 \%$ of the food in developing countries is produced by women yet they face more constraints than men in accessing technology, training and extension services, education, marketing and credit services (High-Level Task Force on Global Food Security, 2010). Quisumbing \& Meinzen-Dick (2001) suggest that improving women's education is one of the single policy instruments that results into increased poverty 
reduction by lowering child mortality and improving health, nutrition, and educational outcomes for children. Reducing gender gaps in agriculture could improve food security by 12 to $17 \%$ among hungry people (FAO, 2011d) because of a resulting 20 to 30\% production increase from women's farms (FAO, IFAD \& ILO, 2010). Empowering women by strengthening their asset (all forms of capital) and by providing legal and institutional measures to guarantee women's access and command over resources is key to achieving food security (Quisumbing \& Meinzen-Dick, 2001). However, targeting women in isolation from men and the society in reducing gender gaps and food insecurity is insufficient (Quisumbing, Meinzen-Dick \& Smith, 2004).

Devereux (2000) indicates that poverty and lack of a robust livelihood base were both a cause and consequence of food insecurity. Food insecurity leads to compromised human well-being at the same time poverty is the most prevalent underlying driver of food insecurity in Southern Africa (Misselhorn, 2005). Harrigan (2008) also points out that the poor are often exposed to food insecurity because they have fragile and limited entitlements and capabilities. Food insecurity in turn can reinforce poverty in terms of poor nutrition, poor health and erosion of assets (Harrigan, 2008). Poverty and food insecurity are intertwined.

\subsubsection{Population, food losses, production and productivity failures}

The state of world population 2011 report indicates that the world population has risen to seven billion (UNPFA, 2011). Population increase is perceived to be exacerbating food insecurity, poverty and threatening the environment (Premanandh, 2011). Long-term trends of slower growth in agricultural production and rapid growth in food demand also contribute to global food insecurity through a sharp downward trend in world aggregate food stocks and increase in food prices (Trostle, 2008).

Food losses contribute to food insecurity in various ways depending on commodities involved, production areas and seasons (Kader, 2005). Globally, about one third of food produced for human consumption is lost or wasted (FAO, 2011b). Food losses refer to reductions in both quality and quantity of food (Premanandh, 2011). Causes of food losses include premature harvesting; lack of effectiveness during mature harvesting; inadequacies in postharvest handling resulting in spillage and degradation; inadequacies in storage and processing; and diseases and pests (FAO, 2011b). This implies that reducing food losses could increase food security both at a global and household level.

Waddington et al. (2010) show that production constraints (abiotic, biotic, management and socio-economic) contribute to food insecurity through reduction in yields and crop productivity. Factors contributing to production constraints vary according to location, farming system, crops, socio-economic factors, and policy and institutional environments. Constraints to production and productivity are well documented and include limited access to quality seed, soil fertility depletion, insufficient access to agricultural information and training, limited access to effective and efficient equipment, weed competition, diseases and pests, limited access to financial services, limited economic access to chemical fertiliser, extreme weather events (climate change), poor crop rotations, inappropriate use of inputs, labour shortage, decreased public expenditure and investment in agriculture, and physical soil degradation (Hesselberg \& Yaro, 2006; Maxwell, Webb, Coates \& Wirth, 2010; Torero, 2011; Umar, Aune, Johnsen \& Lungu, 2011).

\subsection{Options for addressing food insecurity}

Options for addressing household food insecurity are as many as their corresponding causes. These options include reducing losses and wastage, agro-forestry, hydroponics, transgenics, food loss prevention and control, policy reform and regulation, infrastructural development, change in dietary and consumption patterns, cash transfers and climate smart agriculture like conservation agriculture (FAO, 2011c; Popkin, Adair, \& Ng, 2012; Premanandh, 2011; Sabates-Wheeler \& Devereux, 2010).

\subsubsection{Conservation agriculture (CA) and conservation agriculture project (CAP) in Zambia}

Conservation agriculture (CA) is increasingly promoted as an option for addressing food insecurity (FAO, 2011c). CA is commonly defined as a set of agricultural practices with three interrelated core principles: minimum mechanical soil disturbance, permanent organic soil cover and diversified crop species in rotation or associations including legumes (FAO, 2011c; Govaerts et al., 2009; Hobbs, Sayre \& Gupta, 2008). To this concept, Conservation Farming Unit (CFU) added planting of Faidherbia albida for soil fertility improvement and dry season early land preparation (CFU, 2011:78). There are two main variants of CA among smallholder farmers in Zambia: hand hoe based CA and animal draft powered (ADP) ripping.

Figure 1 shows a hand hoe based CA. Hand hoe based CA involves digging of planting basins (CA basins) spaced at 0.7 meters along the rows and 0.9 meters between rows using a Chaka hoe (CFU, 2009b). Crop residues and other vegetative matter are supposed to be retained on surface as permanent organic soil cover in 
the area between basins. Recommended dimensions of a basin are 0.2 meters in depth, 0.3 meters in length and the same width as that of the blade of the Chaka hoe (CFU, 2009b). A Chaka hoe has an elongated thick strong blade and a long handle compared to a traditional hand hoe. These features of a Chaka hoe account for its heaviness ( 4 to $5 \mathrm{~kg}$ ) relative to a traditional hoe. On the contrary, hand hoe based conventional agriculture involves tilling the whole field using a traditional hand hoe or making ridges resulting in maximum soil disturbance.

The animal draft powered CA (ADP ripping) shown in Figure 2 involves using a Magoye ripper instead of a conventional mould board plough. Instead of complete soil inversion as in conventional agriculture with a plough, famers practising ADP ripping (Figure 2) make at least 0.15-0.20 meters deep ripped furrows at 0.9 meters spacing in CA and retain crop residues and other vegetative matter between ripped lines (CFU, 2009a). Minimum tillage restricts soil disturbance to the precise area where the crop is sown resulting into a minimum soil disturbance of around 10\% of the area in both CA basins and ADP CA ripping (FAO, 2011a).

Figure 3 shows a third variant of CA, tractor based form of CA. This mechanised kind of CA (Figure 3 ) is not common among smallholder farmers because of lack of capital, knowledge and access to the machinery.

Since the mid 1990s, the Conservation Farming Unit (CFU) of the Zambia National Farmers Union (ZNFU) has championed the training of both institutions and individual farmers on CA in the country. Conservation Agriculture Project (CAP ) was a donor funded project implemented by CFU from 2007 to 2011 (CFU, 2006). $\mathrm{CA}$ is claimed to offer benefits of increased soil organic matter, improvements in water harvesting, reduction in the risk of crop failure, increased and stabilised yields, reduction in soil erosion, improvement in soil structure, reduced pests and diseases, reduced weed pressure, increased productivity and enhancing food security (Derpsch, Friedrich, Kassam, \& Hongwen, 2010; Li et al., 2011; Marongwe et al., 2011). Despite these potential benefits, there is hardly a study in Zambia that has shown the differences between CA adopters and non-CA adopters in relation to food security from the context of pulses. Hence, the objective of this study was to document the differences in food security between CA adopters and non-CA adopters with reference to pulses. The following research questions were addressed:

1. What are the common pulses grown among smallholder farmers?

2. What are the differences in the spread of growing pulses between CA adopters and non-CA adopters over a period of four consecutive farming seasons?

3. Is there any association between practices of CA (minimum tillage and crop rotation) and access to a meal with pulses in a day?

4. How do smallholder farmers perceive the preference of various legumes promoted under CA project?

5. What are the differences in food security between CA adopters and non-CA adopters in terms of:

a. Cash income from pulses as percentage of total pulses production?

b. Crop diversity?

c. Number of meals with pulses eaten in a day?

6. What are experiences of women regarding conservation agriculture and food security in relation to pulses?

\section{Methods}

Data was collected between June and October each year from 2007 to 2010. This period was chosen because most parts of the study areas were easily accessible by road at that time. Both qualitative and quantitative methods were used in collection and analysis of data.

\subsection{Study area and sampling}

Figure 4 shows the study areas.

The study areas were chosen because CAP was operating in these areas. In this study, a smallholder farmer is defined as households farming on less than 20 hectares (Haggblade \& Tembo, 2003). CFU provided extension services to smallholder farmers in the study areas. Most farmers in the study areas practised mixed farming involving crops like maize, sweet potatoes, cassava, numerous kinds of beans, cowpeas, cotton, sorghum, millet, sweet stalks, pumpkins, water melons and cucumbers. Major types of livestock included cattle, goats, pigs and poultry. The agricultural system is mainly rain-fed and farmers seldom practice irrigation (Siegel \& Jeffrey, 2005). 
CAP had targeted 120,000 smallholder farmers to adopt CA from 2007 to 2011. Using updated CAP registers, 640 farmers were randomly sampled in 2007 for the questionnaire survey. Information was collected from the same households for four consecutive farming seasons 2006/2007 to 2009/2010. The sample size reduced from 640 to 535 in 2008, 486 in 2009 and 440 in 2010 due to deaths, migration, some respondents declining to be interviewed and others simply being absent at the time of the survey. Purposive sampling was used in the selection of key informants and focus group discussants in order to have participants who were known to have opinions and experiences on the topics for discussions.

\subsection{Data collection and analysis}

Questionnaires, focus group discussions, key informant interviews, informal discussions, direct observation, and review of literature were used to collect data. The survey questionnaire was used to collect most of the data on quantitative aspects and the other methods collected mostly data on qualitative aspects.

In addressing the first research question, farmers were asked to name the types of crops that they had grown in a particular season. This data was analysed using percentages to show the common pulses grown among smallholder farmers.

On the second research question percentage of households engaged in growing pulses and a two sample proportional test were used. Data on area under pulses was also collected and a t-test was used to compare the means of CA adopters (indicated by having area under minimum tillage) to non-CA adopters. Mean number of trainings on $\mathrm{CA}$ attended in each year were also compared for CA adopters and non-CA adopters to add to the accounting of results.

For the third research question, firstly, the association between minimum tillage (CA principle) and access to a diet with pulses (food security indicator) and secondly association between crop rotation (CA principle) and access to a meal with pulses were done using chi-square test. A binary logistic regression was used to determine the direction of the association and odds ratio.

Content analysis of information from key informants and focus group discussants on their experiences and concerns raised regarding legumes promoted by the CAP was used to answer the fourth research question on food preference.

Cash income from pulses as percentage of total pulse production was used as an indicator of food security in answering the fifth research question. This indicator was chosen because most smallholder farmers primarily grow crops for home consumption and excess for sale. In this way, percentage of pulses cash income to total pulses production (at market price) is a proxy indicator for food adequacy. It is also a proxy indicator for economic access to other food security requirements. This assumption was checked by simple linear regressions with number of food secure months as a response variable and percentage of pulses cash income as an explanatory variable.

Crop diversity (number of crops grown each farming season) was also used as a proxy indicator for food security assuming a positive relationship between food security and crop diversity. This assumptions was also checked by simple linear regressions with number of food secure months as a response variable and crop diversity as an explanatory variable. Proxy indicators are mostly used to measure food security because no perfect single measure that captures all dimensions of food security concept has yet been found (FAO, 2002; Webb et al., 2006).

T-test was used to assess the differences between CA adopters and non-CA adopters in the means for share of pulse cash income and crop diversity. Results were also triangulated with the differences between CA adopters and non-CA adopters in mean the number of times a meal with pulses was eaten in a day.

Content analysis of information from focus group discussants, key informants, informal discussions and review of literature relating to women's experiences towards food security in relation to pulses was explored to address the sixth research question.

\section{Results and Discussion}

For succinct purposes the farming seasons 2006/2007, 2007/2008, 2008/2009 and 2009/2010 will be referred to as 2007, 2008, 2009 and 2010 in the presentation and discussion of results.

\subsection{Common food legumes grown among smallholder farmers}

Most common pulses grown among sampled smallholder farmers were groundnuts (Arachis hypogaea), cowpeas (Vigna unguiculata), other beans and soya beans (Glycine max) in the order of decreasing prevalence (Figure 5). 
Odendo, Bationo \& Kimani (2011) also report that groundnuts, cowpeas, soya beans and common beans (Phaseolus vulgaris) were the most important pulses in Sub-Saharan Africa.

As shown in Figure 5 it was common for farmers to grow more than one pulse. This is shown by the total percentage of more than 100 in each farming season. Other beans included diversified varieties of common beans (Phaseolus vulgaris), sesame (Sesamum indicum), mbambara beans (Vigna subterranean) and pigeon peas (Cajanus cajan). These pulses were not among the prime food legumes promoted under CAP as pointed out by focus group discussant. Legumes promoted by CFU under CAP included groundnuts, cowpeas, soya beans, velvet beans (Mucuna pruriens), guar (Cyamopsis tetragonoloba) and pigeon peas (CFU, 2006).

Figure 5 also shows an overall increase in the spread of growing pulses over the four farming seasons. This increase came from increased access to extension support through farmer trainings on CA and distribution of legume seeds (mostly cowpeas and groundnuts). The steady and near six fold increase in the spread of growing other beans suggests a positive effect of CFU's extension support to farmers. Key informants confirmed that farmer training on CA conducted under CAP emphasised, among others, on practising crop rotation that includes legumes. These results show that emphasis of the principle of practising crop rotation with legumes was being taken up by farmers to the extent that some farmers had started growing pulses that were not directly promoted by the project. Direct observation during an informal visit in two villages in Chibombo district in 2012 showed that it was more common to find legume fields than at the beginning of Conservation Agriculture Project (CAP). Some informal discussions indicated that men were increasingly getting involved in the process of growing legumes. However, there is need for further investigation on the dynamics of gender relation in line with conservation agriculture and pulses.

\subsection{Extent of growing pulses among $C A$ adopters and non-CA adopters}

The variable, extent of growing pulses, was chosen as a proxy indicator of food security because it allowed analysis of the differences between CA adopters and non-CA adopters in two scale dimensions. The first dimension was the horizontal dimension (spread) measured as percentage of households engaged in growing pulses. The second dimension was a vertical dimension (intensity) of growing food legumes measured as area under legumes.

\subsubsection{Spread of growing food legumes}

In general, the percentage of households having area under legumes showed an increase from $69 \%$ in 2007 to $83 \%$ in 2008; $87 \%$ in 2009 and $95 \%$ in 2010 . This is because of improved access to extension support and access to legumes seeds for planting. Results (Table 1) show, an overall tendency for the percentage of households engaged in growing pulses among $\mathrm{CA}$ adopters to be higher than among non-CA adopters.

The overall differences (all pulses) between CA adopters and non-CA adopters shown in Table 1 were highly significant in the first and fourth farming seasons but marginally significant in the third season. The lack of significance in the second farming season could be due to wide spread flooding that was reported by respondents.

A further analysis of differences between CA adopters and non-CA adopters in individual pulses also gave consistent of results. The spread of growing cowpeas had almost doubled for both CA adopters and non-CA adopters over the four farming seasons despite a decrease recorded in 2008. The spread of growing groundnuts had steadily increased by about $30 \%$ among CA adopters and about $40 \%$ among non-CA adopters. About a threefold steady increase in the spread of other pulses was recorded among CA adopters and a near ninefold steady increase for non-CA adopters. Marginal changes were noted in the case of soya beans. The results show that the spread in growing of pulses was not limited to crops promoted by CA project but extended also to pulses that were important for food security from smallholder farmers' perspective. The overall increase in households growing pulses over time for both CA adopters and non-CA adopters shows that non-CA adopters could have also benefited from CAP extension system. Key informants reported that trainings in CA were open to all farmers. Some non-CA adopters could also have accessed seeds from the CA project though the CA adopters were a priority group.

Cross checking with simple logistic regression with area under legumes as a binary response (1=having area under legumes and $0=$ having no area under legumes) and CA adoption as a binary explanatory variable, similar results were obtained. Positive coefficients: 0.45 (p-value $=0.022)$ in 2007; $0.27(\mathrm{p}$-value $=0.236)$ in 2008; 0.49 ( $p$-value $=0.073)$ in 2009; and coefficient of 1.45 (p-value $=0.005)$ in 2010 were obtained with $1.57,1.31,1.64$, and 4.29 odds ratios respectively. These results mean that in each of the four farming seasons a CA adopter was more likely to grow legumes than non-CA adopter. 


\subsubsection{Area under food legumes}

Area under legumes was used to assess the differences in intensity of growing pulses between CA adopters and non-CA adopters.

For both CA adopters and non-CA adopters, from 2007 to 2008 there was a reduction in mean area followed by a marginal increase in 2009 and a substantial increase in 2010 farming season. Results (Table 2) showed no statistical difference between CA adopters and non-CA adopters. These results indicate that a CA adopter and non-CA adopter generally grow pulses to a similar extent. These findings are coherent to the finding from an adoption study on the same farmers that indicated that practising crop rotation with legumes was a very common practice to both CA adopters and non-adopters (Nyanga, in press). Increased dependency and demand on the project as a source of free seed was noted as it was very common for farmers to complain of not having received enough or not having received any cowpea seeds and/or groundnut seeds from the CA project. These results indicate the need to have sustainable means of access to seed by smallholder farming communities. The substantial increase recorded in 2010 season (Table 2) mostly came from groundnuts and cowpeas (Figure 6).

Figure 6 shows the mean areas and corresponding standard error bars for households engaged in growing respective pulses. Results show significant difference between CA adopters and non-CA adopters in the mean area of other pulses in 2009 season. This could be due to distribution of legumes seeds especially pigeon peas mostly among CA adopters. A few CA adopters reported having got some pigeon peas from the project. Direct observation also showed that some key informants such as lead farmers had small areas under pigeon peas near homesteads in the last two seasons. Discussions with key informants indicated that pigeon pea may not be part of a common diet among smallholder farmers. This was also evident from some farmers who were asking such as: Is this crop (pigeon pea) for food or not? How do you prepare it? This was not the case for cowpeas.

Substantial reductions in mean area for most legumes for both CA adopters and non-CA adopters during 2008 farming season were recorded due to wide spread floods during that farming season. In the case of other pulses, stoppage in growing of velvet beans also contributed to the decrease recorded in 2008. CAP project staffs confirmed the wide distribution of velvet beans in 2007 season and getting complaints from farmers afterwards that the crop could not be easily cooked or sold. A female farmer reported that:

This bean (velvet beans) does not get cooked. It is very hard... needs a lot of water and firewood...The other problem is that there are no people to buy the crop.

The above experience indicate that Velvet beans could increase the burden of women in terms of time spent cooking the pulse and also in terms of increased requirement for water and firewood collection. These results show that there is need to take the smallholder farmers' food preferences and food utilisation dimensions seriously in CA projects.

The mean area for cowpeas did not reduce but instead increased during the farming season with floods. This could have been due to increased access to seed and the growing of the crop twice within a single farming season. Most farmers reported that the variety of cowpeas that they had got from CAP was maturing much earlier than the conventional type. Cases of farmers growing cowpeas twice in a single farming season were also reported.

\subsection{Association between CA practices and consumption of pulses}

Smallholder farmers practising CA were also expected to have one third of their cultivated land under legumes (CFU, 2006). The underlying assumption was that promotion of growing of legumes in CA would translate to increased food security through increased consumption of pulses and cash income. Hence, it was necessary to assess the association, firstly, between minimum tillage and consumption of pulses and secondly, between crop rotation and pulses intake.

Using $24 \mathrm{hrs}$ recalls, on whether a household had eaten a meal with pulses, results showed no significant association between CA principle of minimum tillage and intake of pulses in all the four years (Table 3).

A cross tabulation furthers showed significant association between crop rotation and intake of pulses for the last three seasons (Table 3). The lack of significant association during the first year of CAP implementation, 2007, is partly due to the emphasis of growing velvet beans a legume without common place in the diet of smallholder farmers and also sceptical behaviour of smallholder farmers towards new varieties of food legume seeds.

A binary regression with two categorical explanatory variables; CA adoption (where $1=\mathrm{CA}$ adopter and $0=$ non-CA adopter) and crop rotation $(1=$ yes and $0=$ no) was used to determine the direction and likelihood effect on food security. Food security was measured as a dichotomy response variable of access to a meal with pulses $(1=$ accessed, $0=$ not accessed $)$. 
As shown in Table 4 there was positive and significant effect of crop rotation on likelihood of pulses intake for all the last three seasons. A smallholder household practising crop rotation had an odd about twice higher of having a diet with pulses than a smallholder household not practising crop rotation (assuming common values for other variables).

These results show that access to a diet with pulses is more influenced by the CA principle of crop rotation than the principle of minimum tillage. This suggests that farmers are growing legumes not only on fields under minimum tillage but under conventional tillage as well. Farmers could be using either conventional agriculture or conservation agriculture depending on the type of pulse grown.

Table 4 further shows that minimum tillage especially basins during a season with wide spread floods could have led to decreased likelihood of accessing a meal with pulses. This is indicated by the negative coefficient in 2008 a season with wide spread floods. The negative coefficient for crop rotation in 2007 season is indicative of a possible immediate negative effect of promoting velvet beans on the likelihood of a household having a meal with pulses because it could not be eaten nor sold.

\subsection{Share of cash income to total pulses production}

The differences between CA adopters and non-CA adopters in terms of food security with respect to pulses was also assessed using cash income from pulses as percentage of total pulses production. A simple linear regression showed a significant positive relationship between share of pulses cash income and food secure months (Table 5). The results in Table 5 imply that increase in pulses production increases household food security.

Figure 7 shows mean percentage of pulse cash income to total production with corresponding standard error bars. These results (Figure 7) show firstly, that CA adopters had a tendency to have a higher share of pulses cash income than non-CA adopters. Secondly, results show the negative effect of extreme weather event of flooding in 2008, a one third reduction in pulses cash income as percentage of total pulses produced. This implied increased food insecurity due to extreme weather event. Thirdly, the results indicate a steady two fold increase in the share of pulses cash income over the last three farming seasons. This implies that both CA adopters and non-adopters had similar pattern of improvements in food security vis-a-vis pulses, despite CA adopters having a relatively higher food security status than non-CA adopters. Fourthly, CA adopters and non-CA adopters consumed more than $50 \%$ of their pulses produced. This shows that food insecurity is still a huge challenge. This is because about $70 \%$ for a CA household and $80 \%$ for non-CA adopters of their total pulses produced is mostly shared between household food consumption, post harvest losses, seed for the next farming season, remittances and paying of loans.

\subsection{Crop diversity}

Crop diversity as number of crops grown was also used as an indicator of household food security. Firstly, this indicator was chosen because CA principle of crop rotation does not only stress on the need to involve legumes but also diversified crops. Secondly, the indicator was chosen because of the assumption of existence of a positive relationship between household food security and crop diversity. Crops grown among smallholder farmers included cassava, cotton, cowpeas, maize, soya beans, groundnuts, sunflower, sweet potatoes and other pulses. These nine crops were used in the assessment of crop diversity, in spite that marginal crops such as millet, sorghum, sun hemp and sweet stalks were also grown by sampled farmers. There was also an underestimation because crops like pumpkins, water melons and various types of cucumbers were grown mixed with the major crops. These results show that smallholder farmers have a diversified portfolio of crops that they grow. Regression results confirmed the assumption of a positive relationship between crop diversity and food security (Table 6).

Simple linear regression results (Table 6) show that an increase in crop diversity increases household food security among smallholder farmers, holding other factors constant.

In terms of differences in crop diversity between CA adopters and non-CA adopters, results (Figure 8) show a tendency for the mean number of crops grown to be higher among CA adopters than among non-CA adopters. These differences where significant $(\mathrm{p}<0.001$ in $2007 ; \mathrm{p}=0.009$ in $2008 ; \mathrm{P}=0.025$ in 2009 ; and marginally significant in 2010, $\mathrm{p}=0,050$ ). These results are consistent with findings presented earlier supporting the argument that CA adopters have a tendency to be more food secure than non-CA adopters in relation to pulses. Results were triangulated with number of meals with pulses eaten last 24 hours (Figure 9). Results from 24 hours recall also showed a consistent tendency of CA adopters having relatively accessed more pulses in their diet than non-CA adopters. 


\subsection{Green harvest and women}

Respondents in most focus group discussions noted that households that were practising CA started eating green harvest from CA plots much earlier than those that were not practicing minimum tillage. Discussion with smallholder farmers indicated that most households had CA basin fields often located near homesteads for strategic food security purposes. Management of such fields was often spearheaded by women. Farmers often urged that such fields were an important source of green harvest thus contributing to food security during the usual hunger peak period (October to April). One of the female respondents noted that:

The advantage of CA especially basins is that you start eating the crop from the field earlier than from crops under conventional agriculture... you can also plant this new variety of cow peas twice within one farming season. ...The type of cowpeas from CFU is nice because it does not have "mpengele" (seeds that cannot get cooked).

Another farmer reported that early planting of pulses had offered her opportunity to earn some cash income during the peak food shortage period. This was largely dependent on timely access to output market and individual commitment. The farmer in her 60s explained that:

Previously (before CAP project) I was used to waiting for my groundnuts field to be ploughed after the family main maize field and sometimes after cotton fields (mostly male domain crop) had been planted. As a result, I used to plant late, often planting behind a plough such that germination was not as good as it is when I plant in CA basins. Now, I have (additional) benefits, I plant early in my small CA basin field and later plant my groundnuts on a large ploughed field. The fresh groundnuts (planted early) are very profitable when taken to town (urban market) during January and February.

Cases of men getting more involved in growing legumes were also reported. Men often in informal discussions claimed that women were happy with conservation agriculture because of the emphasis of growing their legumes. These statements indicated that women had an extra voice, the CA trainings, which had influenced men to put relatively more priority on growing of pulses now than before CA project. Generally, legumes were perceived by farmers as a vital means for soil fertility improvement, important for food security purposes, source of fodder, important for reducing soil erosion and suppression of weeds when used as cover crops. Similar results have been reported by Odendo et al. (2011). Among women, pulses were an important source of income. A general perception of respondents was that women were more likely than men to spend their income from pulses on the family consistent with argument for improving food security through reducing gender gaps in agriculture (Momsen 2010).

It was a common view among smallholder farmers that early land preparation in CA plots enabled them to plant earlier than in conventional agricultural fields. Triangulation with results from questionnaires showed that land preparation on average started in the third week of August (21) for CA basins and CA ripping started 30 days later than basins. On the other hand, land preparation on average in conventional hand hoe plots started 68 days later than in CA basins. Similarly, conventional ploughing on average started 94 days later than in CA basins. Each of these mean dates was significantly different $(p<0.05)$ from others. This supports the reports from farmers that land preparation in CA plots is done much earlier than in convention fields. However, the benefits of early land preparation in CA were dependent upon farmer's timely access to planting seed and rainfall distribution that particular season. There is need to investigate further on seasonality and the extent of contribution of CA to household food security through green harvest under varied rainfall distribution taking into account the intra household gender dimensions.

Both women and men expressed knowledge of the importance of pulses as a source of valuable proteins. However, women seemed to be more knowledgeable than men on the diverse ways of preparing pulses for consumption. It was pointed out that some women kept part of the pulses in order to exchange with maize during the frequent hunger peak period (October to April). One of the women explained that:

It is very profitable to exchange groundnuts with maize during the regular period with food shortage. A meda (5 litre container of about 4 to $5 \mathrm{~kg}$ ) of groundnuts is exchanged for at least 20 litres $(20 \mathrm{~kg})$ tin of maize.

The above results show that food security with respect to pulses is mediated by gender. However, storage of pulses was a challenge because most respondents pointed out that rats and other pests were contributing to post harvest losses. 


\subsection{Influential factors}

An interaction of trainings in CA given to farmers and access to seed was a major reason for the differences between CA adopters and non-CA adopters in this study. Among CA-adopters, the percentage of farmers that attended at least one CA training in a year increased from $66 \%$ in the first year to $90 \%$ the following year followed by a slight decrease to $83 \%$ and $80 \%$ for the last two seasons. Among non-CA adopters, the percentage of farmers attending at least one CA training in a year has also increased from $37 \%$ in 2007 to $67 \%$ in $2008 ; 61 \%$ in 2009 and $56 \%$ in 2010 .

The mean number of trainings attended by CA adopters was significantly higher than mean number of trainings attended by non-CA adopters during each of the four seasons (Figure 10). Simple linear regression of number of CA training on crop diversity also showed significant positive effect in all seasons, coefficient $=0.09$ and $p$-value 0.009 in 2007; coefficient $=0.05$ and p-value 0.033 in 2008; marginally significant in 2009 (coefficient $=0.05$, p-values $=0.081$ ) and significant in 2010 (coefficient $=0.08$, p-value 0.016). A correlation between the number of crops involved in rotation and number of CA trainings attended also indicated positive significant ( $p$-values $<0.05$ ) relationship in each of the four seasons though the strength of the relationship was weak, not more than a correlation coefficient of 0.2 each year. Similar results were obtained with a simple linear regression of training on cash income from pulses as share of the total pulses production: coefficient $=0.02$, $p$-value $=0.004$ in 2007; in 2008 coefficient $=0.01$, p-value $=0.014$; in 2009 coefficient $=0.01$, p-value $=0.306$; and coefficient $=0.01$, p-value $=0.015$ in 2010 . The R-square in each case was not more than $4 \%$ implying that other factors such as access to seed, household demography, assets, education and access to output markets could further explain the results in this study. Nonetheless, these results support the argument for the positive effect of CAP extensions system on household food security in relation to pulses. Other studies have also shown a positive and significant effect of CA trainings on adoption of CA practices among smallholder farmers in Zambia (Nyanga, in press).

\section{Conclusion}

This study has shown that the most common pulses grown among sampled smallholder farmers in Zambia were groundnuts, cowpeas, other beans and soya beans in the order of decreasing prevalence. Other beans included diversified varieties of common beans, sesame, mbambara beans and pigeon peas. An increase in percentage of households growing pulses over four farming seasons has also been shown. There was a tendency for the percentage of households growing pulses to be significantly higher among CA-adopters than among non-CA adopters. This is because of a combined effect of CA trainings and increased access to seed that was higher among CA adopters than among non-CA adopters. This study further showed significant association between CA principle of crop rotation and access to a meal with pulses for the last three years. The study has also shown that farmers preferred growing legumes that could be eaten and/or easily sold thus pulses familiar to smallholders' diet were preferred to alien pulses. It has also been shown in this study that cash income from pulses as percentage of total pulses production was higher among CA adopters than among non-CA adopter. Similar results were recorded in the case of crop diversity and mean number of meals with pulses eaten in a day. Cases of women increasing their cash income from pulses because of CA practices and reduction in the intensity of food shortage during the peak hunger period because of early green harvest from CA have also been reported in this study. With reference to pulses, it is concluded from this study that CA adopters are relatively more food secure than non-CA adopters among sampled smallholder farmers in Zambia. Factors contributing to increased food security included farmer trainings in CA, increased access to planting seed, early land preparation and planting made possible by practising minimum tillage, and revitalisation of the practice of crop rotation.

The following concerns are raised: Efforts to increase seed access should further be promoted. There must be political will by donors, national government and international development agencies to promote food legumes that are part of preferred diet instead of promotion of alien species among smallholder farmers. Building from existing and working systems could increase efficiency and effectiveness of CA projects in reducing food insecurity. Setting the CA development agenda right, not sacrificing the livelihood needs of smallholder farmers, is important for any meaningful reversal of household food insecurity through conservation agriculture. Investment in linking farmers to output markets must seriously be addressed if CA projects are to be of much more impact in reducing food insecurity than is currently. Pragmatic ways of reducing gender gaps among smallholder farmers have to be further sought and implemented in CA projects.

\section{Acknowledgments}

I am deeply indebted to my supervisors Professor Dr. Fred H Johnsen, Professor Dr. Jens B. Aune and Dr. Thomson H. Kalinda for their useful input on this paper. My special thanks goes to Noragric $\mathrm{PhD}$ candidates 
peer pressure group for reviewing this paper and my sincere gratitude also goes to the two anonymous reviewers for their suggestions.

\section{References}

Asenso-Okyere, K., Chiang, C., Thangata, P., \& Andam, K. S. (2012). Two-Way Links between Health and Farm Labor. In S. Fan \& R. Pandya-Lorch (Eds.), Reshaping agriculture for nutrition and health, pp. 121-127. Washington, DC: IFPRI.

Burchi, F., Fanzo, J., \& Frison, E. (2011). The Role of Food and Nutrition System Approaches in Tackling Hidden Hunger. International Journal of Environmental Research and Public Health, 8(2), 358-373. http://dx.doi.org/10.3390/ijerph8020358

CFU. (2006). Reversing Food Insecurity and Environmental Degradation in Zambia through Conservation Agriculture. Lusaka: Conservation Farming Unit.

CFU. (2009a). Conservation Farming \& Conservation Agriculture Handbook for Ox Farmers in Agro-Ecological Regions I \& II. Lusaka: Conservation Farming Unit, (Chapter E).

CFU. (2009b). Conservation Farming and Conservation Agriculture Hand Book for Hoe Farmers in Agro-Ecological Regions I \& IIa-Flat Culture. Lusaka: Conservation Farming Unit, (Chapter C).

CFU. (2011). The practice of Conventional and Conservation Agriculture in Eastern and Southern Africa. Lusaka: Conservation Farming Unit.

Derpsch, R., Friedrich, T., Kassam, A., \& Hongwen, L. (2010). Current status of adoption of no-till farming in the world and some of its main benefits. International Journal of Agricultural and Biological Engineering, 3(1), 1-25. http://dx.doi.org/10.3965/j.issn.1934-6344.2010.01.001-025

Devereux, S. (2000). Food insecurity in Ethiopia A discussion paper for DFID. Brighton: IDS Sussex.

Devereux, S., \& Edwards, J. (2004). Climate Change and Food Security. IDS Bulletin, 35(3), 22-30. http://dx.doi.org/10.1111/j.1759-5436.2004.tb00130.x

FAO. (2002). Measurement and assessment of food deprivation and under-nutrition Proceedings of the International Scientific Symposium (June 26-28, 2002), pp. 301-304. Rome, Italy: Rome: FAO.

FAO. (2010a). Country Profile: Food Security Indicators. Country: Zambia Retrieved 16. 04. 2012, http://www.fao.org/fileadmin/templates/ess/documents/food_security_statistics/country_profiles/eng/Zambia_E. pdf

FAO. (2010b). The State of Food Insecurity in the World. Rome: FAO.

FAO. (2011a). Climatic Risk Analysis in Conservation Agriculture in Varied Biophysical and Socio-economic Settings of Southern Africa Network paper 03. Rome: FAO.

FAO. (2011b). Global food losses and food waste: extent, causes and prevention. Rome: FAO.

FAO. (2011c). Socio-Economic Analysis of Conservation Agriculture in Southern Africa Network No. 2. Rome: FAO.

FAO. (2011d). The State of Food and Agriculture. Women in Agriculture. Closing the gender gap for development. Rome: FAO.

FAO, IFAD, \& ILO. (2010). Gender dimensions of agricultural and rural employment: Differentiated pathways out of poverty. Status, trends and gaps. Rome: FAO, IFAD \& ILO.

FAOSTAT. (2011). Prevalence of undernourishment in total population Retrieved 16. 04. 2011, from http://www.fao.org/economic/ess/ess-fs/fs-data/ess-fadata/en/

Govaerts, B., Verhulst, N., Castellanos-Navarrete, A., Sayre, K. D., Dixon, J., \& Dendooven, L. (2009). Conservation Agriculture and Soil Carbon Sequestration: Between Myth and Farmer Reality. Critical Reviews in Plant Science, 28, 97-122. http://dx.doi.org/10.1080/07352680902776358

Haggblade, S., \& Tembo, G. (2003). Conservation Farming in Zambia EPTD Discussion paper no.108: International Food Policy Research Institute.

Harrigan, J. (2008). Food insecurity, poverty and the Malawian Starter Pack: Fresh start or false start? Food Policy, 33(3), 237-249. http://dx.doi.org/10.1016/j.foodpol.2007.09.001 
Hesselberg, J., \& Yaro, J. A. (2006). An assessment of the extent and causes of food insecurity in northern Ghana using a livelihood vulnerability framework. Geojournal, 67(1), 41-55. http://dx.doi.org/doi:10.1007/s10708-006-9007-2

High-Level Task Force on Global Food Security. (2010). Food and nutrition security: Updated Comprehensive Framework for Action. Rome: FAO.

Hobbs, P. R., Sayre, K., \& Gupta, R. (2008). The role of conservation agriculture in sustainable agriculture. Philosophical transactions of the royal society, 363, 543-555. http://dx.doi.org/10.1098/rstb.2007.2169

Kader, A. (2005). Increasing food availability by reducing postharvest losses of fresh produce. Acta Hort, 682, 2169-2175. http://www.actahort.org/books/682/682_296.htm

Li, L., Huang, G., Zhang, R., Bill, B., Guangdi, L., \& Kwong, Y. C. (2011). Benefits of Conservation Agriculture on Soil and Water Conservation and Its Progress in China. Agricultural Sciences in China, 10(6), 850-859. http://dx.doi.org/10.1016/S1671-2927(11)60071-0

Marongwe, L. S., Kwazira, K., Jenrich, M., Thierfelder, C., Kassam, A., \& Friedrich, T. (2011). An African success: the case of conservation agriculture in Zimbabwe. International Journal of Agricultural Sustainability, 9(1), 153-161. http://dx.doi.org/10.3763/ijas.2010.0556

Maxwell, D., Webb, P., Coates, J., \& Wirth, J. (2010). Fit for purpose? Rethinking food security responses in protracted humanitarian crises. Food Policy, 35(2), 91-97. http://dx.doi.org/10.1016/j.foodpol.2009.10.002

Misselhorn, A. A. (2005). What drives food insecurity in southern Africa? a meta-analysis of household economy studies. Global Environmental Change, 15(1), 33-43. $\mathrm{http}: / / \mathrm{dx}$.doi.org/10.1016/j.gloenvcha.2004.11.003

Nyanga, P. H. (In press). Factors influencing adoption and area under conservation agriculture: A mixed methods approach. Sustainable Agriculture Research, 1(2), in press.

Odendo, M., Bationo, A., \& Kimani, S. (2011). Socio-Economic Contribution of Legumes to Livelihoods in Sub-Saharan Africa In M. Odendo, A. Bationo, S. Kimani, A. Bationo, B. Waswa, J. M. Okeyo, F. Maina, J. Kihara \& U. Mokwunye (Eds.), Fighting Poverty in Sub-Saharan Africa: The Multiple Roles of Legumes in Integrated Soil Fertility Management (pp. 27-46). Netherlands: Springer

Popkin, B. M., Adair, L. S., \& Ng, S. W. (2012). Global nutrition transition and the pandemic of obesity in developing countries. Nutrition Reviews, 70(1), 3-21. http://dx.doi.org/10.1111/j.1753-4887.2011.00456.x

Premanandh, J. (2011). Factors affecting food security and contribution of modern technologies in food sustainability. Journal of the Science of Food and Agriculture, 91(15), 2707-2714. http://dx.doi.org/10.1002/jsfa.4666

Quisumbing, A. R., \& Meinzen-Dick, R. S. (2001). Empowering women to achieve food security Focus 6. Policy brief 1 of 12. Washington, DC: IFPRI.

Quisumbing, A. R., Meinzen-Dick, R. S., \& Smith, L. C. (2004). Increasing the effective participation of women in food and nutrition security in Africa 2020 Africa conference brief 4. Washington, DC: IFPRI.

Renzaho, A. M. N., \& Mellor, D. (2010). Food security measurement in cultural pluralism: Missing the point or conceptual misunderstanding? Nutrition, 26(1), 1-9. http://dx.doi.org/10.1016/j.nut.2009.05.001

Riely, F., Mock, N., Cogill, B., Bailey, L., \& Kenefick, E. (1999). Food Security Indicators and Framework for Use in the Monitoring and Evaluation of Food Aid Programs. Washington DC: U.S. Agency for International Development.

Sabates-Wheeler, R., \& Devereux, S. (2010). Cash transfers and high food prices: Explaining outcomes on Ethiopia's Productive Safety Net Programme. Food Policy, 35(4), 274-285. http://dx.doi.org/10.1016/j.foodpol.2010.01.001

Siamwalla, A., \& Valdes, A. (1980). Food insecurity in developing countries. Food Policy, 5(no 4, November), 258-272.

Siegel, B. P., \& Jeffrey, A. (2005). Poverty Reducing Potential of Smallholder Agriculture in Zambia: Opportunities and Constraints Working paper Series No. 85. Washington, DC: World Bank.

Torero, M. (2011). Alternative mechanisms to reduce food price volatility and price spikes Science review: $S R$ 21. London: The Government Office for Science. 
Trostle, R. (2008). Global Agricultural Supply and Demand: Factors Contributing to the Recent Increase in Food Commodity Prices Outlook Report WRS-0801. Washington, DC: ERS, USDA.

Tschirley, D. L., \& Jayne, T. S. (2010). Exploring the Logic Behind Southern Africa's Food Crises. World Development, 38(1), 76-87. http://dx.doi.org/10.1016/j.worlddev.2009.09.008

Umar, B. B., Aune, J. B., Johnsen, F. H., \& Lungu, O. I. (2011). Options for Improving Smallholder Conservation Agriculture in Zambia. Journal of Agricultural Science 3(3), 50-62. http://dx.doi.org/doi:10.5539/jas.v3n3p50

UN. (2011). The Millennium Development Goals Report 2011 (pp. 6-15 Goal 11). New York: UN.

UNPFA. (2011). The State of World Population 2011: People and possibilities in a world of 7 billion. New York: UNPFA.

von Braun, J. (2010). Strategic body needed to beat food crises. Nature, 465(7298), 548-549. http://dx.doi.org/doi:10.1038/465548a

von Braun, J., Ruel, M. T., \& Gillespie, S. (2012). Bridging the Gap between the Agriculture and Health Sectors. In S. Fan \& R. Pandya-Lorch (Eds.), Reshaping Agriculture for Nutrition and Health (pp. 183-190). Washington, DC: IFPRI.

Waddington, S., Li, X., Dixon, J., Hyman, G., \& de Vicente, M. (2010). Getting the focus right: production constraints for six major food crops in Asian and African farming systems. Food Security, 2(1), 27-48. http://dx.doi.org/10.1007/s12571-010-0053-8

Webb, P., Coates, J., Frongillo, E. A., Rogers, B. L., Swindale, A., \& Bilinsky, P. (2006). Measuring Household Food Insecurity: Why It's So Important and Yet So Difficult to Do. The journal of nutrition, 136(5), 1404S-1408S.

Wiesmann, D. (2006). A Global Hunger Index: Measurement Concept, Ranking of Countries, and Trends FCND Discussion Paper 212. Washington, DC: IFPRI.

World Food Programme. (2004). Baseline Food Security Analysis in Iraq. Rome: United Nations World Food Programme.

Ziervogel, G., \& Ericksen, P. J. (2010). Adapting to climate change to sustain food security. Wiley Interdisciplinary Reviews: Climate Change, 1(4), 525-540. http://dx.doi.org/10.1002/wcc.56

Table 1. Spread of growing pulses by CA adoption over four seasons

\begin{tabular}{llllll}
\hline & Farming season & 2007 & 2008 & 2009 & 2010 \\
\hline Cowpeas & CA adopters, \% (n) & $28.6(54)$ & $20.1(56)$ & $30.2(95)$ & $51.8(128)$ \\
& Non-CA adopters, \% (n) & $17.6(72)$ & $8.7(22)$ & $27.9(46)$ & $34.2(41)$ \\
& Z-value & 2.91 & 3.82 & 0.52 & 3.26 \\
& p-value & 0.004 & 0.000 & 0.600 & 0.001 \\
\hline Groundnuts & CA adopters, \% (n) & $67.6(127)$ & $80.2(223)$ & $81.9(258)$ & $88.8(221)$ \\
& Non-CA adopters, \% (n) & $61.4(251)$ & $77.5(196)$ & $74.6(123)$ & $85.5(100)$ \\
& Z-value & 1.48 & 0.77 & 1.83 & 0.86 \\
& p-value & 0.139 & 0.439 & 0.074 & 0.390 \\
\hline Soya beans & CA adopters, \% (n) & $15.3(29)$ & $8.27(23)$ & $16.5(52)$ & $11.3(28)$ \\
& Non-CA adopters , \% (n) & $8.3(34)$ & $7.11(18)$ & $8.5(14)$ & $12.8(15)$ \\
& Z-value & 2.39 & 0.50 & 2.66 & -0.42 \\
& p-value & 0.017 & 0.616 & 0.008 & 0.678 \\
\hline Other pulses & CA adopters, \% (n) & $7.9(15)$ & $9.7(27)$ & $18.8(59)$ & $26.3(65)$ \\
& Non-CA adopters , \% (n) & $3.4(14)$ & $6.7(17)$ & $10.3(17)$ & $26.1(31)$ \\
& Z-value & 2.10 & 1.26 & 2.62 & 0.05 \\
& p-value & 0.036 & 0.207 & 0.009 & 0.957 \\
\hline All pulses & CA adopters, \% (n) & $75.7(143)$ & $84.5(235)$ & $88.9(280)$ & $97.5(234)$ \\
& Non-CA adopters , \% (n) & $66.5(274)$ & $80.6(204)$ & $83.0(137)$ & $90.1(100)$ \\
& Z-value & 2.35 & 1.18 & 1.71 & 2.46 \\
& p-value & 0.019 & 0.237 & 0.087 & 0.014 \\
\hline
\end{tabular}


Table 2. Area (ha) under legumes by CA adoption

\begin{tabular}{lllllllll}
\hline Farming season & 2007 & & 2008 & & 2009 & & 2010 \\
\hline & Mean & Std error & Mean & Std error & Mean & Std error & Mean & Std error \\
CA adopters & 0.36 & 0.05 & 0.32 & 0.02 & 0.34 & 0.02 & 0.54 & 0.03 \\
Non-CA adopters & 0.45 & 0.03 & 0.32 & 0.03 & 0.33 & 0.05 & 0.57 & 0.06 \\
T-value & 1.58 & & 0.03 & & 0.06 & & -0.52 & \\
p-value & 0.116 & & 0.980 & & 0.955 & & 0.602 & \\
\hline
\end{tabular}

Table 3. Association between CA practices (minimum tillage and crop rotation) and intake of pulses

\begin{tabular}{|c|c|c|c|c|c|c|c|c|}
\hline \multirow[t]{2}{*}{ CA practices } & \multicolumn{2}{|c|}{$\begin{array}{l}\text { Pulses intake } \\
2007(n=639)\end{array}$} & \multicolumn{2}{|c|}{$\begin{array}{l}\text { Pulses intake } \\
2008(n=534)\end{array}$} & \multicolumn{2}{|c|}{$\begin{array}{l}\text { Pulses intake } \\
2009(n=478)\end{array}$} & \multicolumn{2}{|c|}{$\begin{array}{l}\text { Pulses intake } \\
2010(n=371)\end{array}$} \\
\hline & Yes & No & Yes & No & Yes & No & Yes & No \\
\hline Used minimum tillage (\%) & 15.5 & 16.0 & 29.6 & 22.8 & 38.5 & 27.6 & 43.9 & 24.0 \\
\hline Minimum tillage not used (\%) & 29.8 & 38.8 & 26.6 & 20.9 & 17.1 & 16.8 & 18.3 & 13.9 \\
\hline Pearson Chi-square & 1.735 & & 0.015 & & 2.738 & & 2.112 & \\
\hline P-value & 0.188 & & 0.904 & & 0.098 & & 0.146 & \\
\hline Crop rotation practised (\%) & 42.2 & 47.3 & 44.9 & 30.9 & 44.1 & 29.7 & 56.3 & 32.4 \\
\hline Crop rotation not done $(\%)$ & 6.7 & 5.8 & 11.1 & 13.1 & 11.5 & 14.6 & 5.4 & 5.9 \\
\hline Pearson Chi-square & 0.002 & & 7.261 & & 9.306 & & 3.989 & \\
\hline P-value & 0.963 & & 0.007 & & 0.002 & & 0.046 & \\
\hline
\end{tabular}

Table 4. Binary regression results of the effect of minimum tillage (MT) and crop rotation (CRT) on access to a meal with pulses

\begin{tabular}{lllllllll}
\hline Season & $2007(\mathrm{n}=601)$ & \multicolumn{2}{l}{$2008(\mathrm{n}=530)$} & \multicolumn{2}{l}{$2009(\mathrm{n}=475)$} & \multicolumn{2}{c}{$2010(\mathrm{n}=367)$} \\
\hline & $\mathrm{MT}=1$ & $\mathrm{CRT}=1$ & $\mathrm{MT}=1$ & $\mathrm{CRT}=1$ & $\mathrm{MT}=1$ & $\mathrm{CRT}=1$ & $\mathrm{MT}=1$ & $\mathrm{CRT}=1$ \\
\hline Coefficient & 0.23 & -0.16 & -0.02 & 0.56 & 0.25 & 0.62 & 0.31 & 0.65 \\
SE of coefficient & 0.18 & 0.25 & 0.18 & 0.20 & 0.19 & 0.21 & 0.23 & 0.33 \\
Odds ratio & 1.26 & 0.85 & 0.98 & 1.75 & 1.28 & 1.87 & 1.37 & 1.92 \\
P-value & 0.184 & 0.526 & 0.908 & 0.006 & 0.206 & 0.003 & 0.172 & 0.048 \\
\hline
\end{tabular}

Table 5. Estimates of effect of share pulses cash income on food secure months

\begin{tabular}{lllll}
\hline Season & $2007(\mathrm{n}=639)$ & $2008(\mathrm{n}=528)$ & $2009(\mathrm{n}=481)$ & $2010(\mathrm{n}=412)$ \\
\hline Coefficient & 0.75 & 1.52 & 1.18 & 1.30 \\
SE of coefficient & 0.35 & 0.46 & 0.40 & 0.34 \\
P-value & 0.035 & 0.001 & 0.004 & $<0.001$ \\
\hline
\end{tabular}

Table 6. Estimates of effect of crop diversity on number of food secure months

\begin{tabular}{lllll}
\hline Season & $2007(\mathrm{n}=639)$ & $2008(\mathrm{n}=532)$ & $2009(\mathrm{n}=481)$ & $2010(\mathrm{n}=361)$ \\
\hline Coefficient & 0.23 & 0.39 & 0.41 & 0.15 \\
SE of coefficient & 0.08 & 0.10 & 0.09 & 0.07 \\
P-value & 0.004 & $<0.001$ & $<0.001$ & 0.045 \\
\hline
\end{tabular}




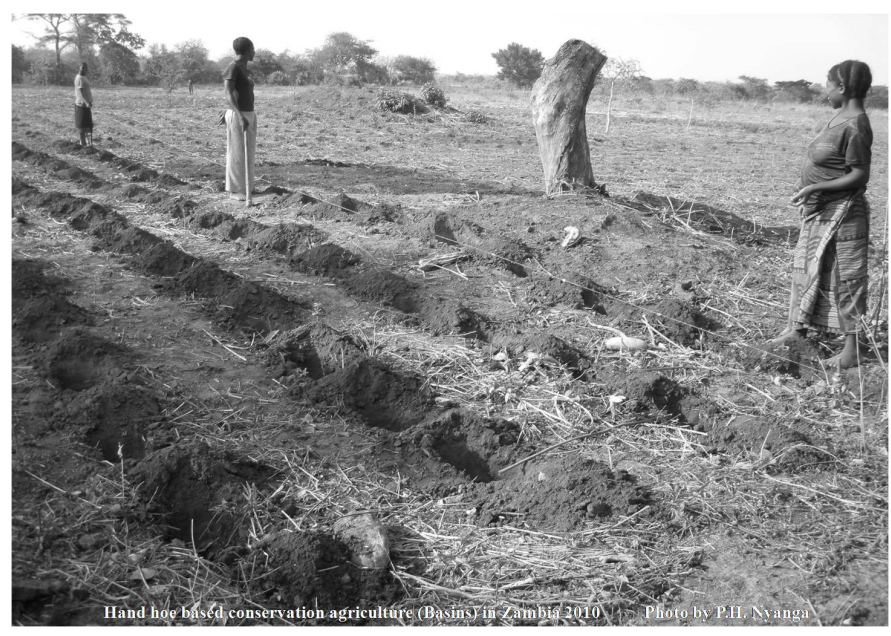

Figure 1. Conservation agriculture basins in Zambia 2010

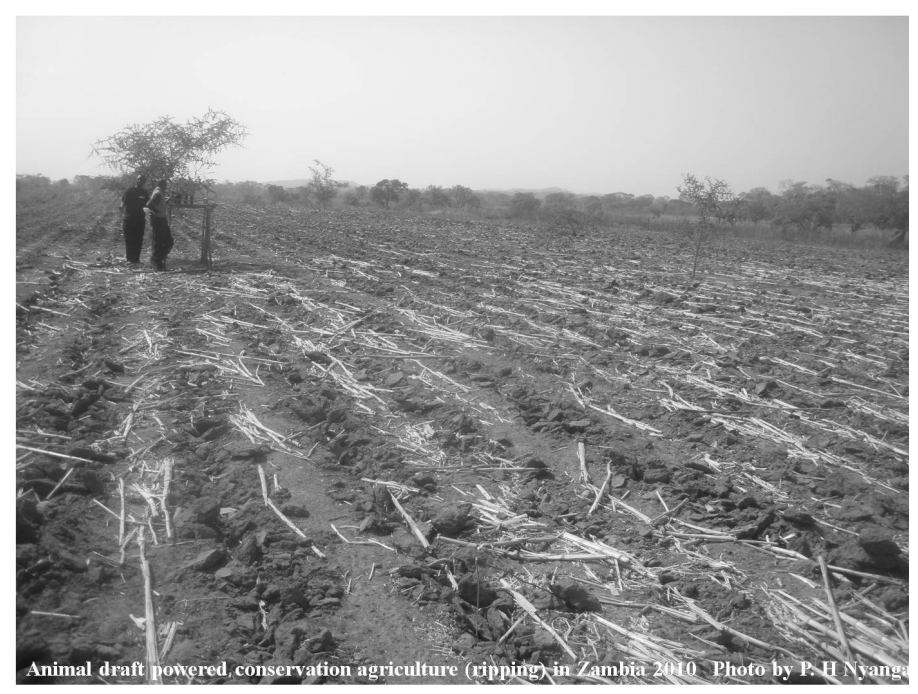

Figure 2. Animal draft powered conservation agriculture (ripping) in Zambia 2010

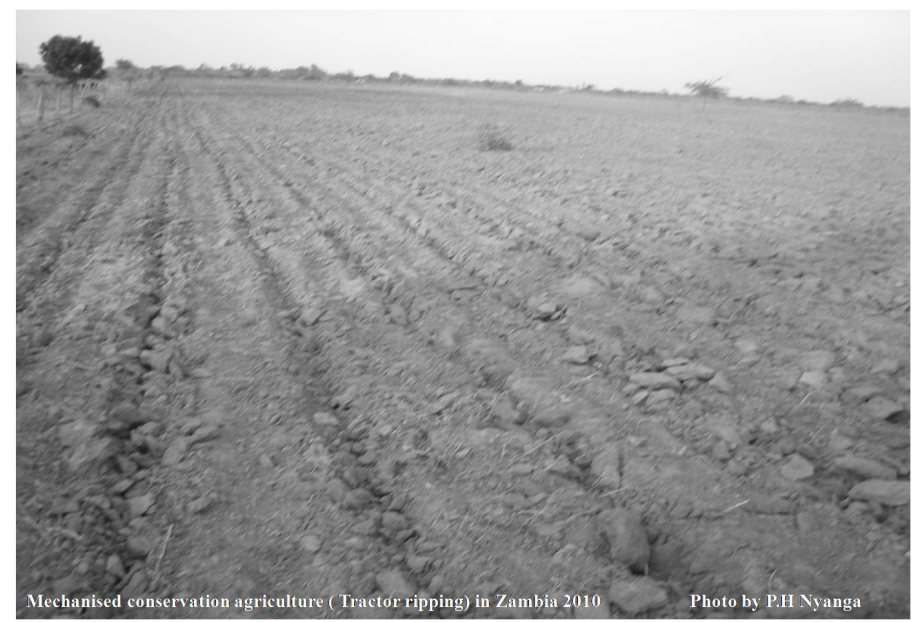

Figure 3. Tractor based conservation agriculture in Zambia 2010 


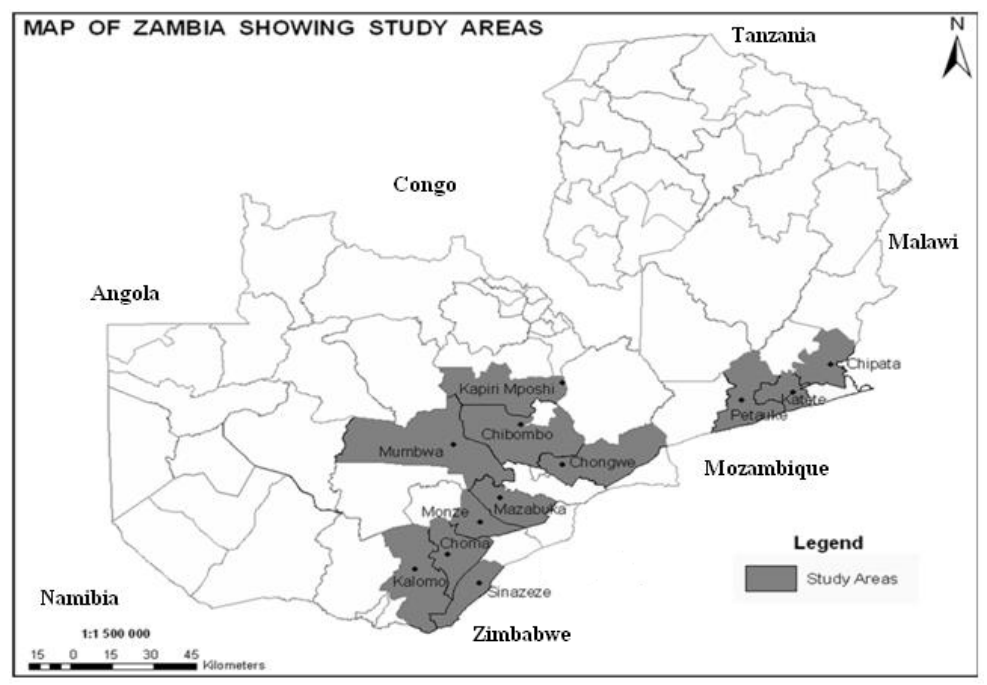

Figure 4. Map of Zambia showing study areas

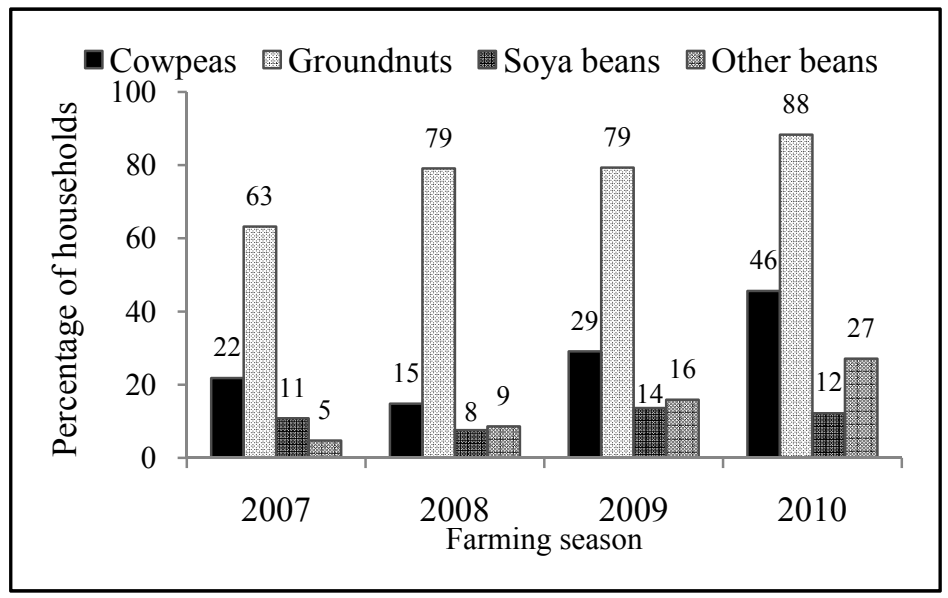

Figure 5. Common pulses grown by farming season 


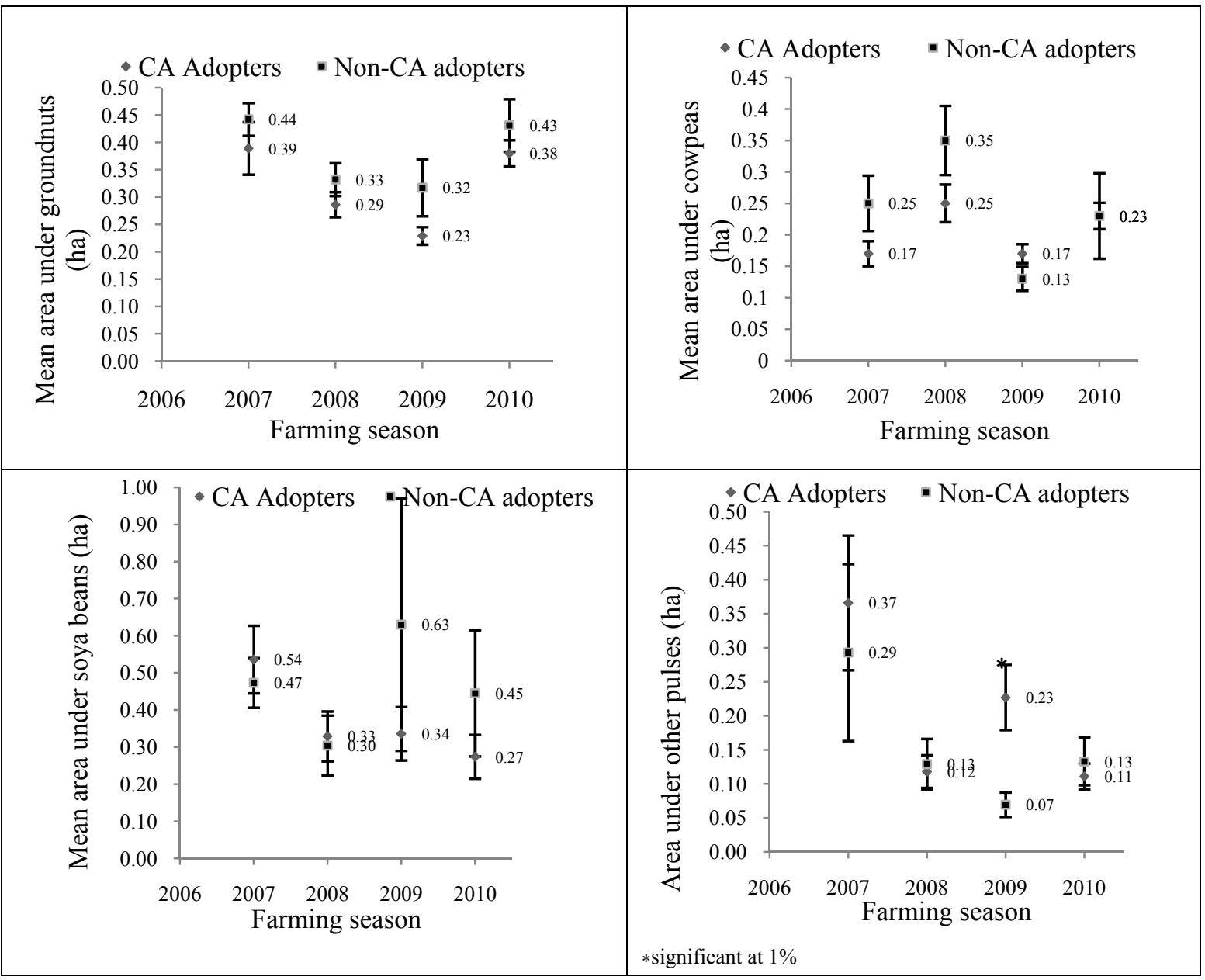

Figure 6. Area under respective pulses by $\mathrm{CA}$ adoption

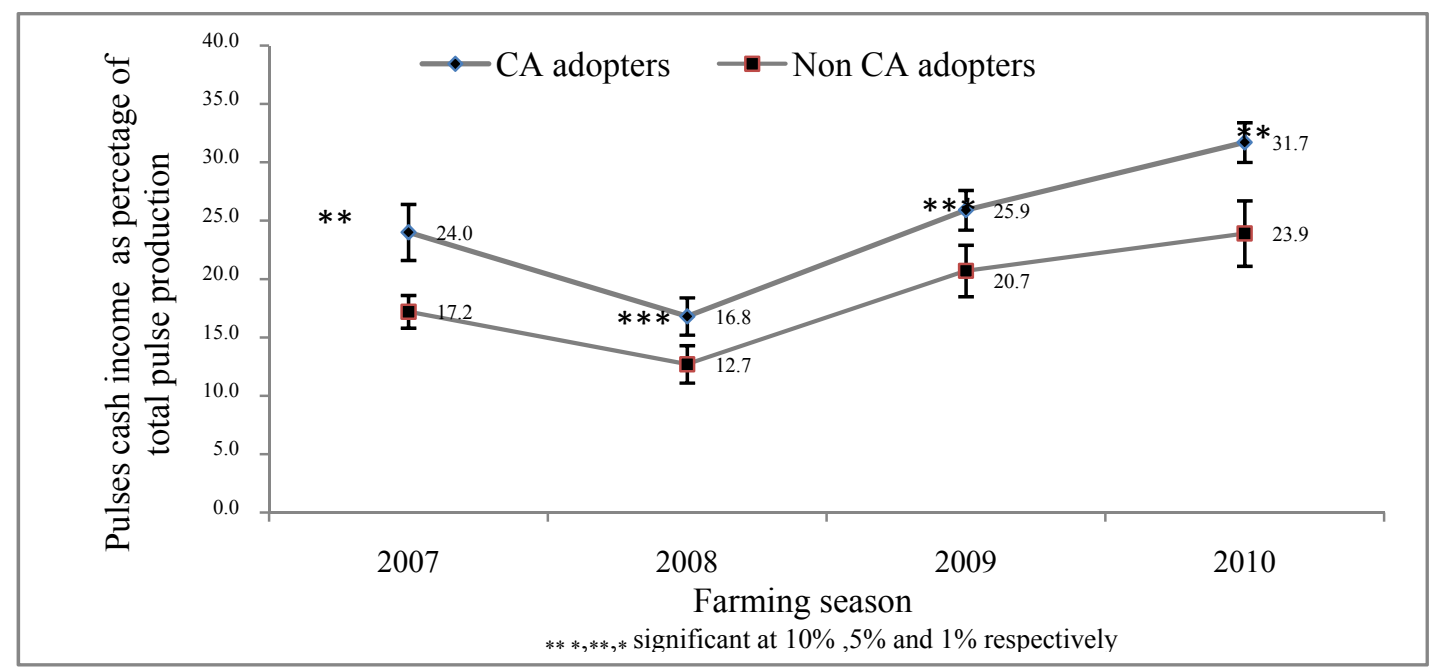

Figure 7. Pulses cash income as percentage of total pulse production 


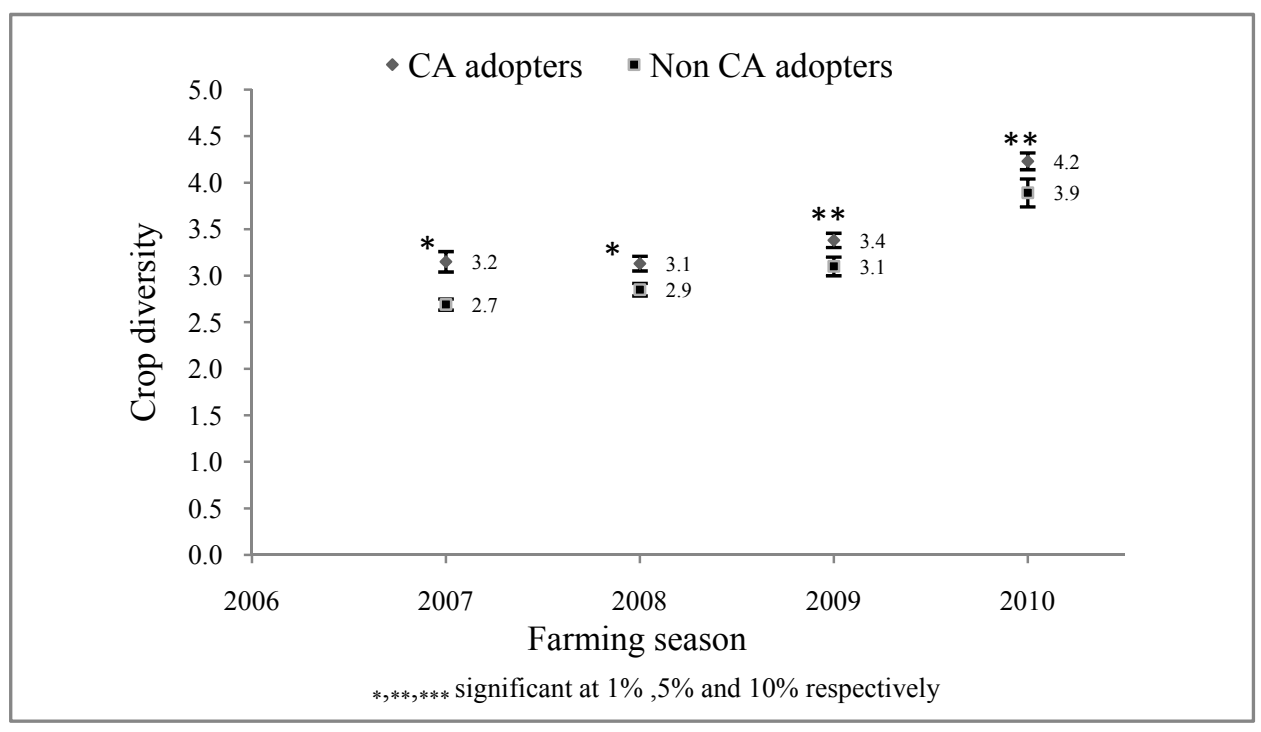

Figure 8. Average number of crops grown by CA adoption

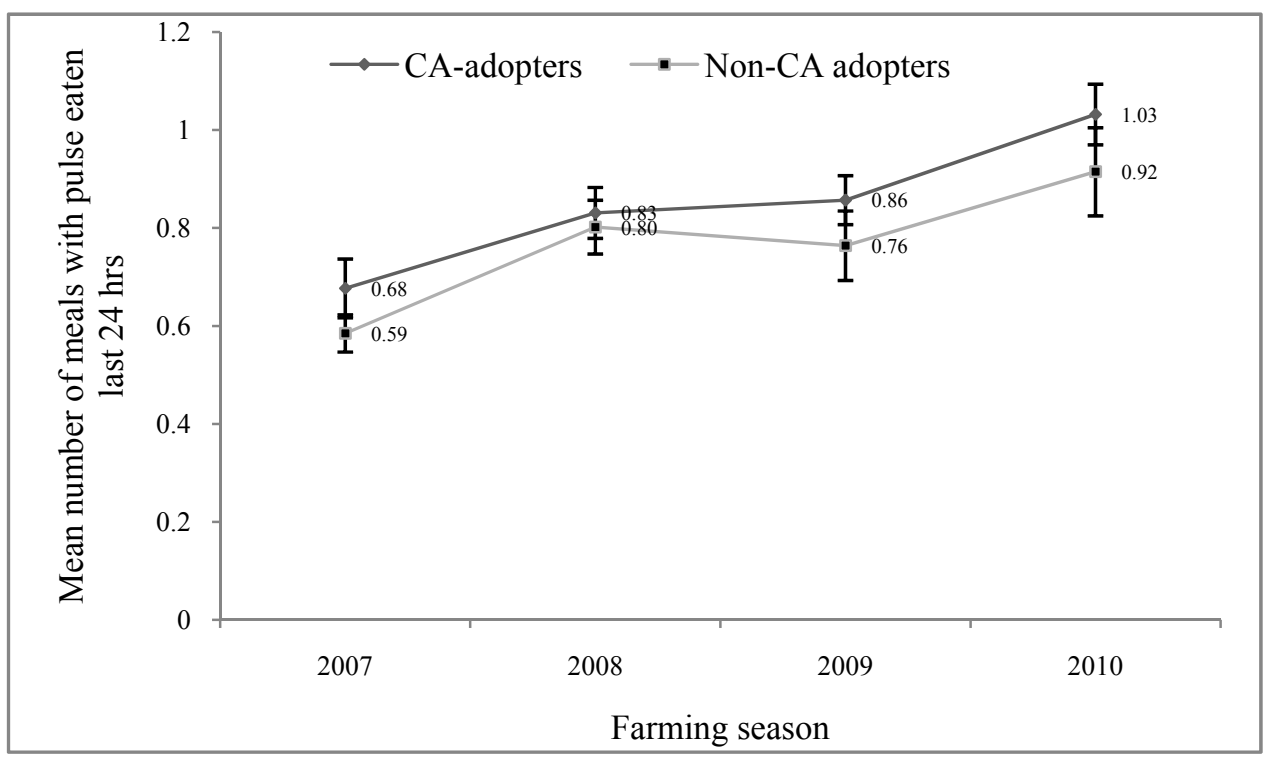

Figure 9.24 hours recall of meals with pulses eaten by CA adoption 


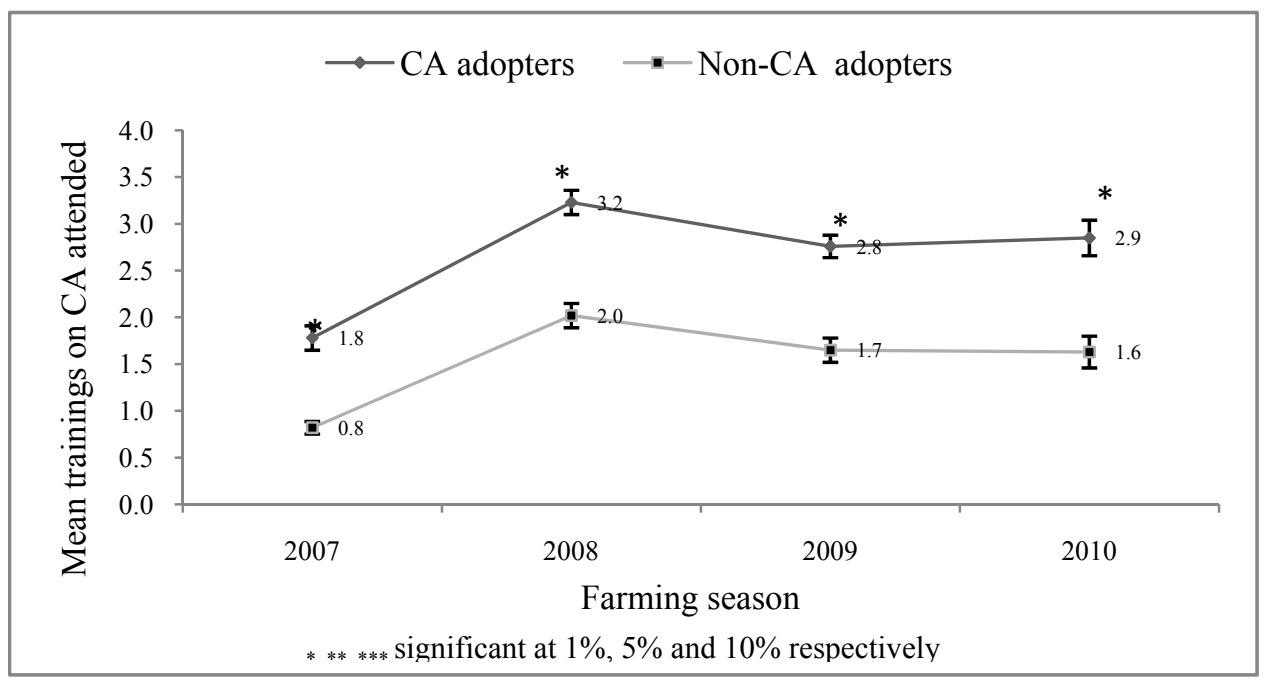

Figure 10. Farmer trainings on Conservation agriculture 